\title{
Facing the Metaphorical Fork: Existentialism in the Identity Formation of Information Systems Students
}

\author{
Saba Rahimi, Elsje Scott \\ University of Cape Town, South Africa
}

\begin{abstract}
A defining characteristic of the Information Systems field is its lack of identity, generic curriculum guidelines and diverse application of curricula across geographic regions, cultural priorities and in line with institutional objectives. This diversity has caused many to feel the field is fluid: one with a multitude of relevant skills, roles and social contexts accepted as relevant to the field. This multitude and inconsistent prioritisation leaves Information Systems students with different skill sets and intellectual priorities. To complicate matters, Information Systems researchers stress the importance of the ability to work in a team, which by design results in further delegation of responsibility and intellectual focus and prioritisation. This research examines the existential elements and identity forming factors caused by exposure to a team environment. In this endeavour it was found that the students identified their first team event as an existential catalyst that spurred identity formation and recognition of their desired identities and intellectual prioritisation.
\end{abstract}

\section{Introduction}

In examining the history of the Information Systems field one is met with debates of identity, undefined and changing boundaries and different areas of focus [3, 14, 20, 28]. A lack of agreed definition and fluidity of "border zones" have resulted in an acceptance that diversity is a fundamental property of the field [1, 21, 29, 32]. An abundance of research identifies a "plethora" of relevant intellectual factors [2] including psychology, sociology, cognition, computer science, strategy, marketing, accounting and operations $[4,28]$. With so many relevant intellectual factors the field is described as "one of the most dynamic fields that has ever existed" [8]. In and amongst the relevant skills needed, authors identify team work as an important non-technical skill required for industry $[8,16,33]$. Teamwork, by design, results in a division of responsibility and a need for specialisation and focus. Therefore one could argue that the importance and need for teamwork result in learners being unable to focus on and prioritize all relevant factors. Our previous focus when reporting on this research was presented at CICE 2016 titled Teamwork: A Metaphorical Fork in the Identity Formation of Information Systems Students. It was concerned with examining the role and effect of teamwork in competency development of Information Systems students. It examined the relationship between group experiences and career trajectory and found the first major team event in their academic careers to be a metaphorical fork pushing students into a career path. Teamwork was also identified as a catalyst that allowed students to move beyond theoretical scenarios and experience a sense of realism which led to motivation, energy, comradeship, confirmation and confidence as well as conflict and tension. This paper focuses more specifically on the existential experiences one faces throughout the teamwork experience. It is argued that teamwork, and working in different teams, spurs a process of cyclical existential questioning that allows students to move away from narrowmindedness. This allows them to recognise their abilities or limitations and move away from being transfixed on a specific role or ideology.

\section{Vast Intellectual Territory}

Diversity and a vast intellectual territory have been introduced as defining characteristics of the Information Systems field. This section examines the implications of the vastness of the field.

\subsection{Many Relevant Social Contexts}

In examining definitions of the field, one may become perplexed by the generic and vague descriptions of the field. Tatnall and Burgees [38] argue the establishment of the field involves a separation from computer science as it "concentrates upon the socio-technical aspects surrounding the implementation and use of ICT in organisations rather than the technical side of systems development" [38]. That is to say, the study of IS involves recognition of information as a resource 
within an organisation that requires management. Historically this created a need for a new profession where technically focused computer scientists would seek to understand the social aspects of business and business requirements in order to enhance processes through technical means.

IS practitioners are focussed on "what people do with the software and each other" thereby "keeping people and organisations in the picture at all times" [24]. Practitioners in the field could act as mediators concerned with knowledge of machines, human behaviour [18] and the symbiotic relationship between these entities. Leidig et al. [27] argue a need for Information Systems practitioners to identify and "design opportunities for IT-Enabled organizational improvement." Improvement would involve "an understanding of what has become possible due to advances in technology" and an "insight into some unmet organisational or societal need" [14]. If one considers these description there are many possible domains in which Information Systems practitioners can operate. Examples can range from debt collection, to finance, to air traffic control, to statistical performances of athletes, to tracing inventory levels in medical institutions. Roode [37] argues that "inappropriate application designs, difficulty of use and outright failure of many systems" are caused by an imbalance of focus between technical factors and an understanding of social contexts. King and Lyytinen [22] agree, describing IT as a "complementary asset in production and operation, and its value cannot be understood without the context of its application." Perhaps one could argue that all social contexts cannot be catered for in development of Information Systems practitioners.

\subsection{Many Available and Relevant Roles}

In addition to a wide range of social contexts, an assessment of literature identified many additional relevant roles and factors. Chao and Shih [9] identified five different categories of relevant skills, namely: 'End-User Support', 'Business Analyst', 'Training', 'Web and Interface Design' and 'Technical Writing.' In contrast Richards et al. [36] identified four categories of radically different skills relevant to the IS field: 'Soft', 'Business', 'Technical' and 'Green', the latter being unique to the study and concerned with sustainable IT practices and reducing effects on the environment. These categories contained a total of 84 skills relevant to the field. Soft skills were regarded as important with skills such as 'ability to learn/lifelong learning', 'analytical/ critical/logical thinking', 'integrity/honesty/ethics', 'business problem solving', and 'responsibility' being emphasised. Similarly to Richards et al. [36], Chao and Shih [9] highlighted vast contrasts in skills required, highlighting that while Business Analysts required testing, quality assurance, and database management skills, Web and Interface Designers require creative and artistic abilities. In this vast intellectual territory with many different possible social contexts and a large number of roles, persistent technological change has caused constant changes to the roles relevant to the field. Hirschheim and Klein [20] argued that the field seemed to travel through history and repeatedly surprise itself with the need to discard its identity in the presence of new hardware capabilities.

\subsection{Embracing Vastness}

Ramos-Torres [32] argued that Information Systems programs are losing "border zones" and traditional focus is being absorbed by closely related fields. Literature shows evidence of opposition to attempts to restrict or control the vastness of the field. Fichman et al. [14] argued that the innovation necessary for operating in the field could be triggered only by emphasis on situations where "requirements are changing and unclear." King and Lyytinen [22] argue that to narrow a field of such intellectual territory and rapid change, would limit its effectiveness. In arguing against advocates of a single solution methodology, Walsham [41] went as far as to state that limiting the vastness of the field with a core focus, boundaries and regulation would serve as a metaphorical "straightjacket" affecting the ability of the field to operate in an interdisciplinary way. Rahimi and Scott [30] argued that curricula do not change quickly enough in response to industry needs. Evidence of movement away from core focus can be found in examining curricula and the history of curriculum development. In developing IS2002 Topi et al. [39] argued that the IS curriculum should "guide" course development rather that "prescribe." Gargone et al. [16], identified four loose areas of focus: knowledge of technology, a non-theoretical understanding of business, ability to analyse and think critically, and communication and team skills. IS2002 called for a combination of these skills to enhance business objectives. The IS2010 are the latest curriculum guidelines and an update to IS2002. Topi et al. [39] describe the IS curriculum as having become more generic in response to encouragement for adaption to institutional and regionally relevant needs [5]. A significant part of IS2010's more generic approach was an acknowledgement that its predecessor, focused narrowly on the business domain and that application existed outside of business social contexts [30]. Domains such as law and medicine could benefit from IS applications [27]. To achieve this IS2010 also encouraged the use of elective subjects to allow a learner to form their own applications in many possible social contexts. IS 
2010 sought to acknowledge an inability to apply IS curriculum globally and consistently. The guidelines became less regulated and left more room for academic institutions to interpret and apply curriculum diversely and inconsistently. In line with Gupta and Wachter's notion that [19] "no single IS curriculum can possibly achieve all of industry's requirements" the IS2010 guidelines also acknowledged that traditional curriculum development had not catered for requirements of non-North American schools. Ezer [13] describes the state of IT education as a comical irony. While IT has possibly played the most significant role in globalisation, not only does IT education not converge to a worldwide standard, but curriculum developers are encouraging flexibility. Lee [25] and Ezer [13] identified inconsistencies between curriculum globally, and Brown et al. [6] identified a need for different applications to cater for the different cultural priorities of students.

Assessing the adoption of IS2010, retrospectively, Leidig et al. [27] found a lack of adaptation by a majority of institutions with there being "no underlying theme, framework across topics." The most contentious point was IS2010's suggestion that programming be made optional. Kroeze et al. [24] argued that its removal would place emphasis on "instrumental knowledge" and reduce the appreciation of the need for analytical thinking skills. Leidig et al. [27] argued that labour statistics proved a demand for programming related jobs in industry. It was also identified that the suggestion to remove programming was largely ignored and in contrast: evidence of increased programming focus were found [27]. In forming a team one might be perplexed about the importance of the programming role as a result of the lack of adherence to guidelines.

\section{Existentialism in Role Selection}

This section defines existentialism and discusses the existential challenges a student may face as a result of being placed in a team and needing to choose a role. These difficulties may arise from having to make uninformed choices about the vast intellectual territory, the abundance or roles, the many social context and persistent disagreement around guidelines, areas of focus and boundaries. This perplexity could be likened to an existential challenge.

\subsection{Existentialism Defined}

A person who possess an existential attitude toward competence development is one who considers themselves as an independent entity [30]; who has their attention focused and directed toward their own nature [15]. Through interaction, reflection and action based on their own standards and wills [30] they seek to develop self-knowledge and selfawareness thereby developing competence. This process involves exposing oneself to the harsh danger of existence and placing oneself in situations which will require them to experience discomfort and ultimately despair at failure as well as joy at success [12]. These exposures are not a unique, once off endeavour, but rather a cyclical process of disintegration, where one leaves one's comfort zone and subsequently "falls apart" [42]. Once this has happened it may lead to positive integration, where one rebuilds oneself at a higher level of understanding [10].

\subsection{The Nature of Information Systems}

The inconsistent application of curriculum combined with the vast and dynamically changing career opportunities present in the field could lead one to argue that there is a lack of agreement about what constitutes IS skills [9,36]. Ramos-Torres [32] argue that vendor and industry certifications add to the challenge faced by academia in creating sufficient curriculum as students may be drawn to various vendor specific qualifications instead of general skills. It is argued that Information Systems Students must take existential initiative to independently investigate the truth of the different perspectives and priorities they are presented with [31]. Reffell and Whitworth [34] present an analogy that an expectation of combined, generally relevant skills would be similar to "summarising squash, snooker, swimming and soccer under the single heading of 'sport' and then going on to believe that all relevant 'sporty' skills can be acquired." Consider the Information Systems student in contrast to a medical student. Medical fields produce standard graduates as general practitioners, within a framework of strict ethical and legal regulation governed by the Hippocratic Oath [17], who can choose to specialise later. In contrast to other fields, the IS student has the pressure of making potentially career defining decisions about specialisation during their undergraduate studies. One could argue that such decisions could be uninformed and the perplexity created by the task of choosing facilitate a small existential crisis. A crisis in which a student would be overwhelmed by the perplexities of choice. In terms of ethics the field of Information Systems is notoriously loose with some describing it as lawless environment similar to the Wild West where: "copyright infringement, piracy, pornography and many other ethically dubious materials" freely distributed [17]. In terms of history, the field itself is one of constant re-creation of focus, revaluation of priorities and rebirth of identity [20], often met with utter surprise [11]. Despite arguments in favour of 
the establishment of ethical codes which Information Systems practitioners could subscribe to, no such codes of conduct exist [7]. One could argue that the path of the Information Systems student and practitioner is one of continuous existential challenges of intellectual prioritisation, ethics and industry wide identity re-creation.

\subsection{Teamwork and Role Stripping}

In addition to the pressure of having to choose a role/specialisation, the effect of teamwork must also be considered. Teamwork by definition involves a separation of roles and responsibilities. There is an abundance of literature $[8,9,16,24,25,32,36,39]$ identifying teamwork and team skills as crucial in helping learners develop skills necessary to gain analytical assessment and interpersonal and communication skills necessary for industry. It is possible that students in a team environment who are unsure or unguided as to the nature of certain roles may face existential challenges in role selection. To complicate matters, the traditional career path, from programmer or analyst to senior management, is no longer relevant with practitioners having varying skill sets based on their career paths [26]. It is likely that being placed in different teams may cause students to face multiple storming phases in their career paths. These may cause role changes or role stripping which is an essential part of existential competence development as "at some point, all of our roles will be stripped from us" which will result in one facing "provocative questions" [42].

Whilst Tuckman [40] conceptualises a relatively smooth four stages of group development (forming when groups come together, storming - when groups experience initial conflict and clashes, norming when groups come to some form of agreement and start being productive, performing - when teams are motivated and knowledgeable) it is possible and likely that Information Systems students may face lengthy time or even become stuck in the storming phase. There may be a need for Dabrowski's [10] existential disintegration (where one breaks down) and positive reintegration (where one transcends to a higher level of understanding) to occur resulting in an uncomfortable process of identity evaluation and reformation. Intuitively one may feel the most provocative questions, the largest existential crisis and the most potent event of disintegration could be caused by a student's first major project experience. One may feel the need to research and examine the effect this event has on students.

\section{Research Design}

\subsection{Research Purpose}

Like vastness, a lack of identity and inconsistent application of curriculum characterise the field [28], there are many roles and specialisations with no real agreement of priorities and focus. As a result of this, it was argued that choosing a role or specialisation may be a naïve or uninformed decision, raising perplexing questions about ones desired identity that could be influenced by a team environment. Whilst research has been conducted about the differing focus and prioritisation on a global [13,25], institutional [27], and cultural level [6], there is a lack of research into the effect of differentiation on an individual level in the field. The authors feel, if it is accepted that global, institutional or cultural priorities can effect a student, there is a need to examine the effects of the first team event on an individual students role and career choice. In assessing the peers' influence on an individual's growth and career trajectory this research focusses on examining the existential identity forming experiences, a student may have while working in a team.

\subsection{Research Sample and Philosophy}

This research comprises a case study with an interpretive analysis of participant responses. Interpretive research recognises the value of analysing unique circumstances [23] and an inability to negate personal experiences and interpretation from the subject under study [35]. There is a recognition that each instance of research is a "unique historical occurrence" [23] that cannot be separated from its unique cultural environment. Qualitative analysis was conducted of the reflective accounts of project and teamwork experiences of Information Systems graduates from the University of Cape Town. The sample was cross sectional as opposed to longitudinal as data was collected in 2012 and 2014 from a sample of 44 graduates (who graduated over a period of 5 years) with different levels of experience and exposure to industry. For ethical reasons no willing interviewees were excluded from the sample. Ethical clearance was obtained from the Faculty of Commerce at the University of Cape Town twice during the study.

\subsection{Data Treatment and Analysis}

Data was collected in the form of 34 face to face audio recorded semi structured interviews and 10 email questionnaires. The interview and questionnaire were designed through a cyclical process of consultation and intended to allow the respondent to 
reflect on their first team experience and how it may have effected them. Audio files were personally transcribed and proof read by the author. This allowed for deeper understanding and reflection on the responses. By conducting an interpretive thematic analysis, which that reality is a social construct and involves "sense making" analysis without predefined variables [23], of the qualitative data, responses were examined, coded and categorised in by their relevance to the initial concerns of the researcher. In addition new concerns were induced and presented.

\section{Findings}

Through evaluating responses it was found that the first team experience acts as a metaphorical fork in the path of Information Systems students and as an existential catalyst motivating learners to pick an area of specialisation. Figure 1 provides a graphical representation of the findings that are discussed in the sections that follow.

\subsection{Teamwork is a Catalyst}

All 44 of the participants identified their first major group experience, a third-year project that included all stages of the SDLC (Software Development Life Cycle) in groups of 4 to 5 people, as the most significant part of their development. 31 of these participants $(70.45 \%)$ made statements that explicitly highlighted the teamwork involved in this project as a central part of their development. Teamwork was described as key to career development. A respondent described team members who were competent and just as passionate as the most significant part of his development. Teamwork provided real project management exposure as people who had different strengths and weaknesses were placed in the same space.

The responses indicated evidence that students had experienced existential disintegration and positive reintegration. Disintegration, and despair, came as a result of their going through Tuckman's storming phase where they faced situations which were awkward, quite tough and nasty. By having to find one's own strength within the team students had to disintegrate not only in their roles but also selfdetermined visions for their team. Under these circumstances conflict resolution exercises were undertaken to enable movement towards Tuckman's forming and norming stages. By engaging with peers they had to reintegrate into new roles with new dynamics and collectively integrate toward a shared direction. These situations provided a sense of realism that exposed learners to situations beyond academia not replicable in textbooks where theories and concepts became tangible. Although there was tension and conflicts, surprisingly no participants expressed bullying or felt that they were bullied into their role.

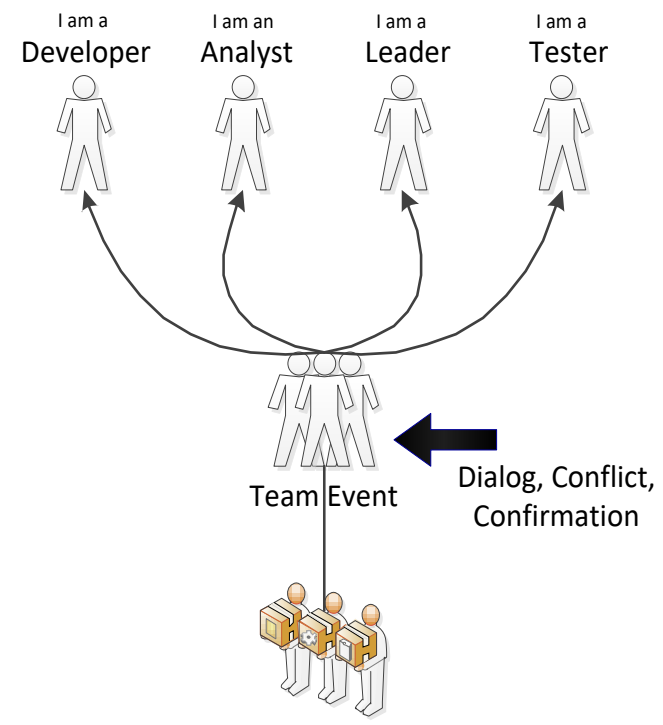

General Skills

Figure 1. Main Elements of Findings

In contrast there was an element of comradeship where students learned a lot and fed off on each other's learning energy, whilst motivating, pushing themselves and pushing each other.

\subsection{Individual Maturing}

Whilst the effect of team work and its influence was established as a catalyst for existential growth evidence was also found of students taking personal responsibility in retrospectively reflecting on the project. In analysing responses there was a large number of pronouns and a recognition of the requirement to self-teach themselves through situations and analyse: what did I do wrong, what did I do right? Some respondents remarked that teamwork created the opportunity for some to develop their leadership capabilities. A respondent remarked: I guess knowing that I wanted to be the team leader the following year I knew it was very important that I develop those skills. The danger of isolation and the usefulness of team experience were emphasised by a participant who drew strength and confidence from confirmations from the team who were happy with their performance. Another participant concurred expressing difficulty in finding motivation in isolation and an inability to motivate himself. Through having input from other people while working on a team he claimed to learned 8 times faster. Students seem to have recognised the need to be in a team, face discomfort, disintegrate their self-established notions and step out of their 
comfort zones and then reintegrate into a new identity and role within their team. In terms of Figure 1, team work resulted in learners moving away from being passive recipients with general skills into an environment that sparked dialog, constructive conflict and confirmation of ability.

\subsection{Project Experience - a Metaphorical Fork in the Road}

The dialog, constructive conflict and confirmations of ability experienced during the first project instance resulted in existential disintegration which manifested itself in the form of role stripping, or recreation, and acted as a metaphorical fork in the road, or career path, which lead to learners specialising and focusing on a certain role or intellectual area. This existential disintegration can be quantified through assessing the responses related to changes in roles. It was found that $24(54.55 \%)$ respondents changed roles as a result of their first project experience. Although, 8 of the 24 participants $(33.33 \%)$ stayed in their role they expressed that they had ventured deeper and had a better understanding of the nature of their adopted role. The team experience was one which allowed slotting into roles, everyone finding their comfort zone and what they were good at. One respondent remarked that: The fact that we were in a group and we sort of found our own strength within that group, so certain people were good at certain things which meant that you necessarily couldn't be the strength in that area, so you sort of found your areas so I found myself being pushed into that more analyst documentation role. A learner could be dynamic enough to switch roles and also be exposed to other areas. One could argue that being placed in a team was provocation that leads to learners choosing roles, thereby sending them on a certain career trajectory and forming an identity around that role. Commitment to a role could be seen as an identityforming commitment. In terms of Figure 1, learners would find their own strength in a role and diversify responsibility amongst themselves before embarking on a career trajectory and retrospectively declaring their identity.

\section{Synthesis}

In examining the findings in relation to the literature four main elements stand out. These elements are graphically represented in Figure 2 and discussed in this section.

Firstly, the students confirmed the widely agreed upon sentiment that teamwork was an essential skill needed $[8,9,16,24,25,32,36,39]$ to grow as Information Systems practitioners. Teamwork was primarily identified as essential in developing interpersonal and communication skills. Students stated that it allowed them to find their own strength and through co-operation they learned a lot and fed off on each other's learning energy.

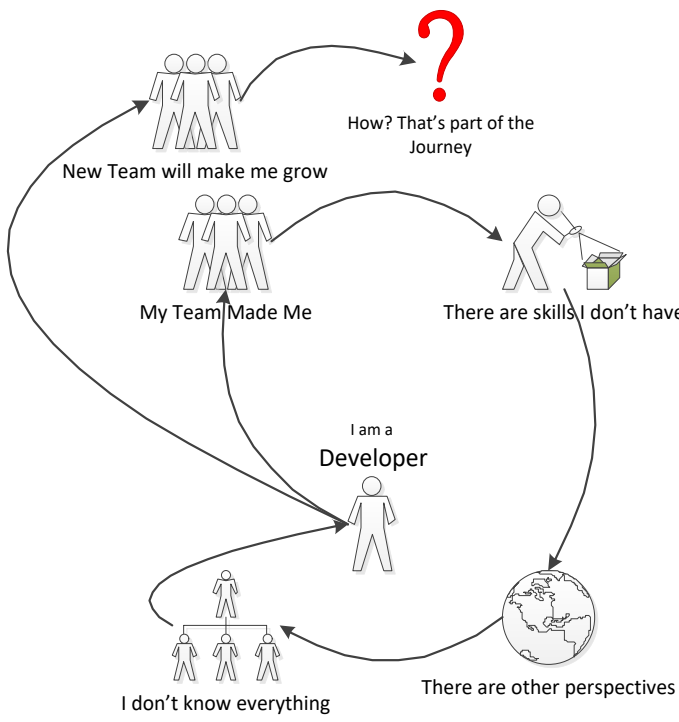

Figure 2. Conceptual Overview

Teamwork enabled people who had different strengths and weaknesses to form identities around roles. In relation to Figure 2, one could say that the learner's identity in the first place was formed by being in a team. Secondly students confirmed literatures identification of vast contrasts relevant skills and roles (one study identifying five [36] with another identifying four relevant [9] categories with an array of diverse skills between categories from analysis to creative abilities) relevant to the field. Rather than causing perplexity and bullying the students felt teamwork enabled them to form their own identity by slotting into roles and everyone finding their comfort zone. The first team event provided an environment that allowed one to disintegrate their self-perception and then experience positive reintegration with a new identity corresponding to the role they established within the team. In relation to Figure 2, one could say learners acknowledged their place within a team and gained an awareness of their strengths and limitations (skills they don't have). Thirdly, there was no evidence of awareness or concern over literatures discussion about the rapid technological changes [20], geographical [13] and cultural challenges [6] causing an inability of curriculum to achieve industry needs [26,27]. Students were aware of other perspectives (globe shown in Figure 2) but acknowledged that they needed to follow their own path and that by being enrolled in an institution that they had obtained a basic framework that provided kind of the minimal basics that you need to survive in terms of being able to go into an organisation. Lastly, in 
relation to Reffell and Whitworth's [34] analogy (the inadequacy of athletes participating in different sports could acquire 'sporty' skills), students acknowledged they had learned initial lessons (not knowing everything as shown in Figure 2). Taking initial lessons and being placed in a new team allowed them to apply the lessons learnt successfully and confidently do things correctly in another context with another perspective. The expressed desire to reapply and apply lessons learned implies an awareness of the need to constantly revaluate and place oneself in different circumstances, each providing lessons and forming part of a journey of identity creation.

One could argue that the provocative questions, existential crisis and disintegration caused by facing the metaphorical fork of the first project experience enabled students to be humbled and be more in tuned with the limitations of their abilities.

\section{Conclusion}

This research sought to examine the effect of the first group experience on career trajectory by assessing the role teamwork could play in shaping a student's specialisation. The researcher found no evidence of any bullying into roles. In contrast, in the process of conducting this research a noteworthy amount of evidence was induced suggesting the importance of team work in career development and as a catalyst for existential driven growth. Having team mates, allowed learners to move beyond theoretical scenarios and experience a sense of realism led to both positive (motivation, energy, comradeship, confirmation and confidence) and negative experiences (conflict and tension). These interactions of storming and forming, then norming and performing, facilitated an existential process of disintegration and positive reintegration in which students saw themselves in a new light and also recognised the value in placing themselves in different situations. The first team experience, as argued becomes a metaphorical fork pushing learners on a career trajectory, also provided an opportunity for learners to realise their preferences and create an identity around a role by finding their strength within their team.

\section{References}

[1] Banville, C. \& Landry, M. (1989). Can the Field of MIS be Disciplined? Communications of the ACM, 32(1), 48-60.

[2] Beard, D., Schwieger, D. \& Surendran, K. (2007, 1921 April). Incorporating Soft Skills into Accounting and MIS Curricula. Paper presented at the 2007 ACM SIGMIS CPR Conference on Computer Personnel Research: The global information technology workforce. (ACM), New York, USA
[3] Benbasat, I. \& Zmud, R. W. (2003). The Identity Crisis within the IS Discipline: Defining and Communicating the Discipline's Core Properties. MIS Quarterly, 27(2), 183-194.

[4] Bernroider, E.W.N, Pilkington, A. \& Córdoba, J.R. (2013). Research in Information Systems: A Study of Diversity and Inter-disciplinary Discourse in the AIS basket Journals between 1995 and 2011. In Journal of Information Technology, 28(1), p3-35

[5] Brewer, J., Harriger, A. \& Mendonca, J. (2006). Beyond the Model: Building an Effective and Dynamic IT Curriculum. Journal of Information Technology Education, 5(1), 441-458.

[6] Brown, I., Moola, I., Mugjenkar, A. \& Sands, M. (2008). Impediments on the Path to Academic Success in an IS Degree Programme: a South African perspective. South African Computing Journal, 41, 64-74.

[7] Bryant, A. \& Land, F. (2012). Discursive Formations and Trans-Disciplinary Agendas: A Response to Walsham. Journal of Information Technology, 27(3), 249-254.

[8] Cappel, J. (2001, 3-5 August). Skills of Information Systems Graduates: An Exploratory Study. Paper presented at the 7th Americas Conference on Information Systems (pp. 1932-1935). Boston, MA, USA

[9] Chao, C. \& Shih, S. C. (2005). Organizational and End-User Information Systems Job Market: An Analysis of Job Types and Skill Requirements. Information Technology, Learning, and Performance Journal, 23(2), pp. 1-15.

[10] Dabrowski, K. (with Kawczak, A., \& Piechowski, M. N.). (1970). Mental growth through positive disintegration. London: Gryf.

[11] Dahlbom, B. (1996). The New Informatics. Scandinavian Journal of Information Systems, 8(2), 29-48.

[12] Dreyfus, H. L. (1999). Anonymity Versus Commitment: The Dangers of Education on the Internet. Ethics and Information Technology, 1(1), $15-21$.

[13] Ezer, J. (2006). India and the USA : A Comparison through the Lens of Model IT Curricula. Journal of Information Technology Education, 5(1), 429-440.

[14] Fichman, R.G., Dos Santos, B.I., Zheng, Z.E. (2014). Digital Innovation as a Fundamental and Powerful Concept in the Information Systems Curriculum. MIS Quarterly, 38(2), 329-353.

[15] Gardiner, P. (1988). Kierkegaard: A very short introduction. Oxford University Press.

[16] Gargone, J. T., Davis, G. B., Valacich, J. S., Topi, H., Feinstein, D. L. \& Longenecker, H.E. Jr. (2002). IS 2002 Model Curriculum and Guidelines for Undergraduate Degree Programs in Information Systems. Communications of the Association for Information Systems, 11(1), 1.

[17] Goodfellow, R. \& Hewling, A. (2005). Reconceptualising Culture in Virtual Learning Environments: from an "essentialist" to a "negotiated" perspective. E-Learning and Digital Media, 2(4), 355 $-367$.

[18] Gregor, S. (2006). The Nature of Theory in Information Systems. MIS Quarterly, 30(3), 611-642. 
[19] Gupta, J. N. D. \& Wachter, R. M. (1998). A Capstone Course in the Information Systems Curriculum. International Journal of Information Management, 18(6), 427-441.

[20] Hirschheim, R. \& Klein, H. K. (2012). A Glorious and Not-So-Short History of the Information Systems Field. Journal of the Association for Information Systems, 13(4), 188-235.

[21] King, J. \& Lyytinen, K. (2003). When Grasp Exceeds Reach: Will Fortifying our Theoretical Core Save the Information Systems (IS) Field? People and Computers: Twenty-one Ways of Looking at Information Systems: Festschrift Celebratinge Markku Nurminen's $60^{\text {th }}$ Birthday, ed. T. Jarvi and $P$. Reijonen, vol. TUCS General Publication, (26), pp. 143-166.

[22] King, J. L. \& Lyytinen, K. (2006). Information Systems The State of the Field. In John Wiley Series in Information Systems. John Wiley \& Sons, Ltd.

[23] Klein, H. K. \& Myers, M. D. (1999). A Set of Principles for Conducting and Evaluating Interpretive Field Studies in Information Systems. MIS Quarterly, 23(1), 67-93.

[24] Kroeze, J. H., Lotriet, H. H., Mavetera, N., Pfaff, M. S., Postma, D. J. v. R., Sewchurran, K. \& Topi, K. (2011). ECIS 2010 Panel Report: HumanitiesEnriched Information Systems. Communications of the Association for Information Systems, 28(24), 373392.

[25] Lee, C. K. (2005, 14-15 April). Transferability of Skills over the IT Career Path. In Proceedings of the 2005 ACM SIGMIS CPR conference on Computer Personnel Research (pp. 85-93), Atlanta, GA, USA

[26] Lee, S., Koh, S., Yen, D. \& Tang, H.-L. (2002). Perception Gaps between IS academics and IS Practitioners: an Exploratory Study. Information \& Management, 40(1), 51-61.

[27] Leidig, J., Leidig, P. \& Ferguson, R. (2014). University Responses to the IS 2010 Model Curriculum: A Pre and Post Comparison, Proceedings of the Information Systems Education Conference, Baltimore, Maryland USA.

[28] March, S. T. \& Niederman, F. (2012). The Future of the Information Systems Discipline: a Response to Walsham. Journal of Information Technology, 27(2), 96-99.

[29] Orlikowski, W. J. \& Baroudi, J. J. (1991). Studying Information Technology in Organizations: Research Approaches and Assumptions. Information Systems Research, 2(1), 1-28.

[30] Rahimi, S.R. \& Scott, E. (2015). The Existential Journey of Information Systems Students, Proceedings from the Ireland International Conference on Education, Dublin, Ireland.

[31] Rahimi, S.R. \& Scott, E. (2016). Information Systems Students as Independent Investigators of Truth, International Journal of Technology and Inclusive Education (IJTIE), Special Issue Volume 3 (1).

[32] Ramos-Torres, A.I. (2013). Current IS Program Challenges and Proposed Strategies to Address Them. Issues in Information Systems, 14(2), 101-108.

[33] Ramos-Torres, A.I. (2015). Analysing an Information System Program Skill-Set: A Bottom Up Validation of a Top Down Design, Issue in Information Systems, 16(3), 80-89.
[34] Reffell, P., \& Whitworth, A. (2002). Information Fluency: Critically Examining IT Education. New Library World, 103(11/12), 427-435.

[35] Reiners, G. M. (2012). Understanding the Differences between Husserl's (Descriptive) and Heidegger's (Interpretive) Phenomenological Research, Nursing \& Care, 1(5).

[36] Richards, D., Marrone, M. \& Vatanasakdakul, S. $\left(2011,30^{\text {th }}\right.$ November $-2^{\text {nd }}$ December $)$. What does an Information Systems Graduate need to know? A focus on Business Analysts and their role in sustainability. In $22^{\text {nd }}$ Australasian Conference on Information Systems, Sydney, Australia.

[37] Roode, J. D. (1993). Implications for Teaching of a Process-Based Research Framework for Information Systems. In Paper presented at the 8th Annual Conference of the IAIM, Orlando, FL, USA.

[38] Tatnall, A. \& Burgess, S. (2009). Evolution of Information Systems Curriculum in an Australian University over the Last Twenty-Five Years. IFIP Advances in Information and Communication Technology, 302, 238-246.

[39] Topi, H., Valacich, J. S., Wright, R. T., Kaiser, K., Jay F. Nunamaker, J., Sipior, J. C., \& de Vreede, G.J. (2010). IS 2010: Curriculum Guidelines for Undergraduate Degree Programs in Information ystems. Communications of the Association for Information Systems, 26(1), 18.

[40] Tuckman, B. W. (1965). Developmental sequence in small groups, Psychological Bulletin 63(6), 384-399

[41] Walsham, G. (2012). Are We Making a Better World with ICTs? Reflections on a Future Agenda for the IS field. Journal of Information Technology, 27(2), 8793.

[42] Webb, J. (2016). Dabrowski's Theory and Existential Depression in Gifted Children and Adults, Retrieved $18^{\text {th }} \quad$ July, 2016 from http://www.davidsongifted.org/SearchDatabase/entry/A10554 